\title{
LA MUÑECA OTOMí ANTE EL EXTRACTIVISMO EPISTÉMICO
}

\author{
THE OTOMÍ DOLL IN THE FACE OF EPISTEMIC \\ EXTRACTIVISM
}

\author{
Imelda Aguirre Mendoza ${ }^{\star}$ \\ Julio César Borja Cruz ${ }^{\star *}$ \\ DOI: https://doi.org/10.31644/ED.V7.N2.2020.A08
}

Resumen: El presente artículo tiene por objetivo discutir algunas consecuencias de las prácticas extractivistas efectuadas sobre la muñeca confeccionada por los otomíes del sur de Querétaro. Se tomarán como ejes de análisis el aprovechamiento que de este artefacto han hecho investigadores, empresarios y dependencias gubernamentales. Al final se verá cómo este tipo de extractivismo se encuentra estrechamente ligado con políticas más amplias que han convertido "el tema indígena" en un campo rentable, susceptible de ser mercantilizado, en el cual se banalizan los conocimientos nativos.

\footnotetext{
* Investigadora del Grupo de Investigación Interdisciplinaria sobre la Región Centro-Noreste de México, Instituto Nacional de Antropología e Historia, México. Líneas de investigación: sistemas míticos y rituales, organización social y construcción del territorio entre poblaciones pame (xỉiui) y teenek de Querétaro y San Luis Potosí. Correo-e: pulikbuk@gmail.com

** Estudiante del Doctorado en Antropología Social en El Colegio de Michoacán, A.C, México. Líneas de investigación: organización social, sistemas de cargos y danzas en comunidades otomíes de Querétaro. Correo-e: borjacruz.jc@gmail.com

Fecha de recepción: 08/01/2020. Fecha de aceptación: 23/03/2020. Fecha de publicación: $31 / 07 / 2020$
}

(cc) BY-NC-ND Páginas $222-244$ 
Palabras clave: muñeca otomí, extractivismo epistémico, conocimientos nativos, turismo, patrimonialización.

Abstract: The purpose of this article is to discuss some consequences of extractivist practices carried out on the doll made by the Otomi people of southern Querétaro. We analyze as a central point the use that researchers, entrepreneurs and government agencies have made of this artifact. At the end, it will be seen how this type of extractivism is strictly linked to broader policies that have converted "the indigenous theme" into a profitable field, susceptible to be commercialized, in which the native knowledge is trivialized. Keywords: otomí doll, epistemic extractivism, native knowledge, tourism, heritage.

\section{Introducción}

En la última década un sinnúmero de saberes artesanales y textiles procedentes de los pueblos originarios han sido aprovechados de manera exponencial por empresas, dependencias gubernamentales, investigadores, organizaciones y actores diversos que los utilizan con fines de lucro. Basta recordar el caso de la blusa tradicional mixe, elaborada en Santa María Tlahuitoltepec, Oaxaca, cuyo diseño fue usurpado por Isabel Marant, quien incluyó los patrones gráficos de dicha prenda en su colección primavera-verano del año 2015, omitiendo la autoría de aquella comunidad (Pérez, 2015). Otra situación paradigmática fue cuando la marca española Mango retomó sin consentimiento un conjunto de bordados originarios de Tenango de Doria -comunidad otomí del estado de Hidalgo- y otros detalles de huipiles oaxaqueños y faldas itsmeñas, los cuales incluyó en su colección otońo-invierno de 2017.

Los artesanos otomíes del sur de Querétaro no han quedado exentos de la problemática aludida. Las muñecas que confeccionan se han convertido en un proyecto rentable para festivales promovidos por dependencias gubernamentales y para la creación de marcas que buscan implementar innovación a partir de la tradición, entre otros escenarios en los que se ha intentado lucrar con dicho saber.

Este artículo tiene por objetivo discutir el caso de la muñeca otomí, planteado como un fenómeno de extractivismo epistémico, ya que no sólo se 
trata de expoliar el objeto para convertirlo en mercancía, sino de apropiarse de las ideas para transformarlas en capital económico y/o simbólico (Grosfoguel, 2016: 133).

Para una mayor comprensión, antes será preciso recurrir a la categoría de extractivismo en términos generales, misma que se verá vinculada con la de extractivismo epistémico a la luz de los datos obtenidos sobre la muñeca en cuestión, los cuales son producto de registros etnográficos efectuados en poblaciones otomíes del municipio de Amealco, Querétaro, entre los años 2014 y 2019, algunos de éstos han sido complementados con consultas de carácter hemerográfico.

\section{Extractivismo y extractivismo epistémico: las categorías de análisis}

Siguiendo los planteamientos de Acosta, el extractivismo es un concepto que ayuda a explicar el saqueo, acumulación, concentración, devastación (neo) colonial, así como la evolución del capitalismo moderno e incluso las ideas de desarrollo y subdesarrollo -como dos caras de un mismo proceso- (2016: 26). En las prácticas extractivas no importa la sustentabilidad de los proyectos y, por lo tanto, el agotamiento de los recursos, en muchas de éstas se prioriza en la exportación antes que en el consumo interno. De acuerdo con las apreciaciones de Gudynas, los gobiernos progresistas latinoamericanos han generado una corriente neoextractivista caracterizada por la fragmentación territorial y, como consecuencia de ello, la delimitación de áreas relegadas y enclaves extractivos asociados a los mercados globales. En dicho paradigma "más allá de la propiedad de los recursos, se reproducen reglas y funcionamiento de los procesos productivos volcados a la competitividad, eficiencia, maximización de la renta y externalización de impactos" (Gudynas en Acosta, 2012: 11). Bajo este escenario es que se han venido agravando los impactos sociales $y$ ambientales en los países del llamado sur global.

Para dicho autor, los extractivismos son "directos" cuando hay una apropiación directa -valga la redundancia- de los recursos desde el medio ambiente, como ocurre con la megaminería o la industria pesquera. El extractivismo es "mediado" cuando primero se modifica el ambiente para luego extraer los recursos necesarios, tal es el caso de la deforestación que se debe implementar para dar pie a las agroindustrias (Gudynas, 2015: 19). 
Además de la industria y los megaproyectos, hay una serie de actividades que cuentan con tintes extractivistas, entre ellos se puede mencionar el turismo en masa que trae consigo impactos socioambientales. A esto se le suma la producción maquinizada que se vende con diseños "tradicionales", en la cual la artesanía ${ }^{1}$ es vista como etnomercancía, es decir, "como un objeto de valor de uso que en el momento de entrar en distintos circuitos de exhibición, venta y consumo revela un valor socialmente creado" (Castillo, 2017: 174). En este espacio se inserta la comercialización que se ha hecho, sin consentimiento, de las creaciones textiles y artesanales de los pueblos originarios a manos de grandes corporaciones, empresas locales y un conjunto de actores que lucran con éstas. Es así como la producción artesanal comienza a verse como un proceso inmerso en el capitalismo, movilizado por la producción, la circulación y el consumo, en el cual se integran productores y consumidores (Novelo, 1976; Ariel de Vidas, 2002).

En términos de John y Jean Comaroff (2011: 10, 57), se ha venido configurando una economía de la identidad basada en etnomercancías, en las que se reúne, por un lado, la experiencia ancestral, y por otro, la apertura a la innovación, la capacidad de reproducir ciertos objetos de manera infinita, pero sin perder su carácter esencial. Las etnomercancías permiten al consumidor hacerse la idea de portar un producto, hasta cierto punto exótico, que lo acerca a determinada cultura con la que pretende identificarse; pero esto es solo una ilusión, pues el producto fue hecho para ser vendido, fue diseñado a partir de las necesidades que se les imputan a dichos consumidores, mientras que al interior del grupo creador, el objeto en cuestión tiene intenciones y significados muy específicos.

En este sentido es que el extractivismo en el saber hacer indígena no sólo lucra con artefactos que se transforman en mercancías sino con el uso y la apropiación de una identidad étnica y de una concepción particular que se

\footnotetext{
${ }^{1}$ La categoría de artesanía ha sido abordada desde distintos enfoques, teniendo como referentes pioneros las propuestas de Novelo (1976) y García Canclini (1981). No es nuestra intención profundizar en la construcción de dicho término, no obstante, siguiendo las formulaciones que Ariel de Vidas realizó sobre los textiles andinos, éste podrá ser entendido "según diferentes puntos de vista: para los productores, se trata de una ocupación económica que combina una tradición artesanal y los imperativos del mercado; para los consumidores, de una manifestación indígena que responde a una búsqueda de exotismo nacida de una necesidad de alteridad; finalmente, para los intermediarios que la hacen circular no es más que un medio de sacar provecho de esa interacción” (2002: 10-11).
} 
tiene sobre el mundo. Dicho fenómeno puede ser mejor comprendido con la categoría de extractivismo epistémico planteada por Grosfoguel, con ésta se alude a la práctica en la que se cosifican conocimientos "con el propósito de extraerlos y explotarlos para beneficio propio sin importar las consecuencias" (2016: 126). El extractivismo epistémico "expolia ideas de las comunidades indígenas, sacándolas de los contextos en que fueron producidas para despolitizarlas y resignificarlas desde lógicas occidentalo-céntricas" (ídem: 133), con el propósito de mercadearlas y transformarlas en capital. Se incurre en éste cuando objetos, tecnologías o ideas producidas por las culturas indígenas son extraídas sin tomar en cuenta a los pueblos que los produjeron (ídem: 113).

Los artefactos e ideas expoliadas cuentan con sentidos particulares dentro de sus contextos de origen, los cuales quedan desplazados cuando se convierten en meras mercancías y se insertan en otros contextos de producción y consumo. Retomando las palabras de Grosfoguel, "este principio de asimilación es epistemicida porque termina destruyendo los saberes y las prácticas ancestrales" (ídem: 139).

Bajo este marco, en lo que sigue discutiremos cómo ha actuado el extractivismo epistémico en el caso de las muñecas confeccionadas por los otomíes de Amealco, municipio al sur de Querétaro, tomando como problemáticas de análisis: la invención de las muñecas Xahni - perteneciente a la marca Yosoyoho-, el Festival Nacional de Muñecas Artesanales, la declaratoria de Amealco como Pueblo Mágico y la incidencia que en ello tuvo la muñeca en cuestión, así como la creación de la muñeca monumental "Lele", por parte de Gobierno de Estado de Querétaro. Antes será preciso brindar algunos antecedentes sobre el origen de esta clase de muñecas como una producción indígena de la región.

\section{El origen de la muñeca otomí}

La llamada "muñeca artesanal mexicana" se confecciona en varios estados de la República, principalmente entre poblaciones otomíes y mazahuas. Se trata de una muñeca de tela caracterizada por la forma circular de su cabeza -por ello también se les conoce como "muñecas de bola"-, dos trenzas y un tocado de listones. Regularmente se les viste con falda y blusa de tela cambaya o con trajes tradicionales similares a los de las mujeres indígenas que las elaboran. 
El origen de esta clase de muñecas tuvo lugar en la década de 1970, cuando el gobierno de la Ciudad de México creó el Centro de Capacitación Mazahua y el Centro Otomí, los cuales tenían como objetivo reducir la venta ambulante del primer cuadro del centro histórico, llevada a cabo por mujeres mazahuas y otomíes emigrantes, que desde los años 40 ya se desempeñaban en dicha actividad (Arizpe, 1979). La idea era capacitarlas en la manufactura de colchas, manteles, cubrecamas, etcétera, y que los centros fungieran como intermediarios en la venta (Romer, 2013; Oehmichen, 2015: 201), para así evitar que las mujeres recurrieran al ambulantaje.

En este espacio se crea la muñeca que nos ocupa, proyectándose como un producto más para el comercio. Los centros de capacitación no tuvieron éxito $^{2}$, al menos en su objetivo de impedir el ambulantaje, ya que las mujeres continuaron vendiendo en la calle carpetas bordadas, frutas, dulces, cigarros e incorporaron la muñeca de tela.

Un gran número de mujeres otomíes que participaron en estos centros provenían de la comunidad de Santiago Mexquititlán, población localizada en el municipio de Amealco, Querétaro. Cuando ellas regresaron a su lugar de origen, instruyeron a otras sobre cómo hacer muñecas, así, dichos conocimientos se transmitieron entre un gran número de pobladores. Al respecto, Antonia Tomás, mujer otomí de 28 años (Santiago Mexquititlán, $15 / 08 / 2014)$, menciona que fue hace aproximadamente treinta años cuando su mamá salió a trabajar hacia la Ciudad de México. Al poco tiempo regresó a la comunidad trayendo consigo unos moldes para hacer muñecas, así comenzaron a confeccionarlas y a venderlas en Amealco y las poblaciones cercanas.

Por otro lado, durante los años noventa, la entonces Comisión Nacional para el Desarrollo de los Pueblos Indígenas (CDI) —ahora Instituto Nacional de los Pueblos Indígenas (INPI)_, promovió este saber entre las mujeres otomíes, al desarrollar una serie de talleres en donde eran instruidas en el arte de hacer muñecas.

Aunque la muñeca se derivó de una estrategia para limitar el comercio informal, paradójicamente se convirtió en una las principales artesanías que

\footnotetext{
${ }^{2}$ Cristina Oehmichen escribe que al término del sexenio de Echeverría (1970-1976) los recursos destinados para esos espacios disminuyeron considerablemente. Las artesanas señalaban que no les pagaban lo justo y los dirigentes del centro las excluían en la toma de decisiones sobre la venta de sus productos (2015: 201).
} 
las mujeres otomíes venden de manera ambulante, y desde hace varios años se ha conformado como una de las principales fuentes de ingresos para las familias indígenas de la región.

Semejante a la indumentaria de las mujeres otomíes, el vestido de cada muñeca reúne un conjunto de elementos bordados en punto de cruz, entre los que sobresalen las serpientes que "traen agua"; las mariposas que en la comunidad de San Ildefonso Tultepec son consideradas almas de los difuntos y/o antepasados. Otra de las figuras de los bordados es la mata del maíz, el cual, como alimento, tiene especial relevancia en la vida de las poblaciones indígenas y campesinas. Alrededor de este cultivo se pueden apreciar prácticas que develan un conocimiento del entorno: saber cuándo sembrar a partir de la observación de las fases de la luna, cómo medir la humedad de la tierra, qué tipo de grano es el indicado para conservarlo con el fin de sembrarlo en la próxima temporada.

Ilustración 1. Muñecas de bola

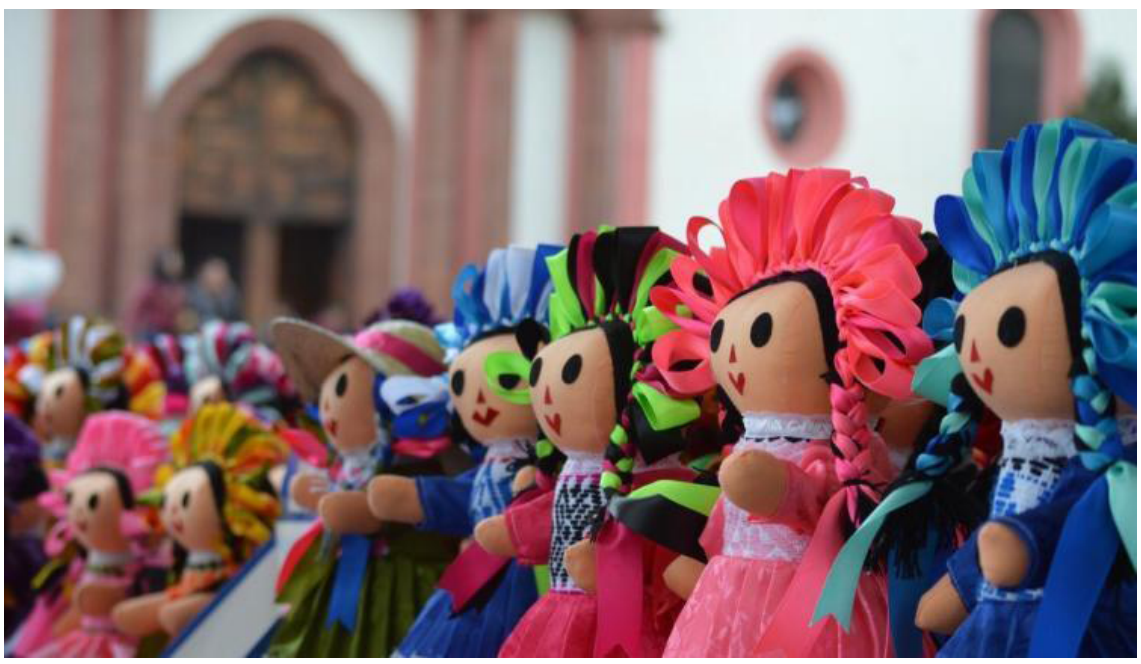

Fuente: Este fin se realiza el Festival Nacional de Muñecas Artesanales en Amealco (Alerta Qro, 2019)

Hay varios diseños para bordar flores: Doni koti, "flor bordada”, Donni noni, k’eñä, "flor dos culebra” y Bola doni, "flor bola". En San Ildefonso Tultepec, las flores son pensadas como objetos bellos debido a que sus colores, formas y 
olores se ligan a categorías como vida, fertilidad, abundancia y alegría (Borja, 2017).

En los bordados también se aprecian aves de pie y de perfil. Un ave importante para la cosmología otomí es el águila, la historia fundacional de varios pueblos se encuentra vinculada a la presencia de ésta y su posterior desplazamiento a Tenochtitlán. Arturo Gómez (2012) escribe sobre el águila bicéfala presente en los mitos de la creación del mundo contados en San Pablito, comunidad otomí al norte del estado de Puebla. En esos relatos dicha ave se relaciona con el sol, la luna y el movimiento; su figura es plasmada en los textiles, particularmente en quexquémetls, así como en el papel amate y el papel china con usos rituales.

Además de los bordados, las muñecas llevan listones en sus trenzas o como parte del tocado. Éstos, por sus cualidades sensibles, como sus colores, su forma y su movimiento, se asocian con lo alegre, con la belleza y con la vida. Los colores seleccionados suelen ser los más vistosos y "fuertes", lo cual nos reitera las nociones de belleza para la población otomí, es decir, nos muestra una concepción local de lo estético.

Las muñecas comercializadas por empresarios y otros intermediarios se venden al margen de todos estos contenidos. Dichos actores han expoliado el saber-hacer indígena persiguiendo intereses concentrados en la ganancia de capital, la promoción turística y las declaratorias de patrimonio que favorecen a unos cuantos sectores, tal y como veremos en lo que sigue.

\section{La muñeca Xahni}

Xahni es una muñeca de tela que tiene el mismo diseño que las muñecas otomíes, la diferencia es que en su interior lleva un dispositivo electrónico que reproduce frases en hñönhö con su traducción al español. Se trata de un producto registrado por una empresa llamada Yosoyoho, procedente de la ciudad de Querétaro.

Las personas que distribuyen la muñeca no son otomíes, se trata de gente que ha trabajado con poblaciones indígenas del estado de Querétaro, como es el caso del representante de la empresa, quien es antropólogo. Desde el año 2016, integrantes de dicha microempresa han presentado el proyecto de la muñeca Xahni en varios espacios y medios informativos. Román Souza, su representante, describe a Yosoyoho como: 
una empresa queretana, [de] aproximadamente siete colaboradores, entre pedagogos, socioterritoriales, antropólogos, sociólogos, que estamos preocupados por reconocer los usos y costumbres de los pueblos indígenas, [...], también tenemos allí el carácter aplicado, entonces queremos que nuestros juguetes en Yosoyoho ayuden a la resolución de los problemas contemporáneos de estos pueblos (TvUAQ, 2016).

Por este carácter "aplicado" y "comprometido con la sociedad", dicha empresa creó un objeto "innovador" y atractivo: Xahni, apelativo que traducen como "transmitir conocimiento". Como ya lo mencionamos, se trata de una muñeca "tradicional" que en su interior lleva un dispositivo electrónico, y al oprimirlo reproduce frases en otomí y su traducción al español. De igual forma, en la falda lleva bordadas palabras en dicha lengua y su equivalente en español. Según ese grupo de microempresarios, la razón de estas innovaciones responde al propósito de que con la muñeca se contribuya a la revitalización de la lengua otomí. Las palabras bordadas y los audios se anuncian como tácticas pensadas para que los hñöñö no dejen de hablar su idioma.

Ilustración 2. "Xahni, la muñeca bilingüe"

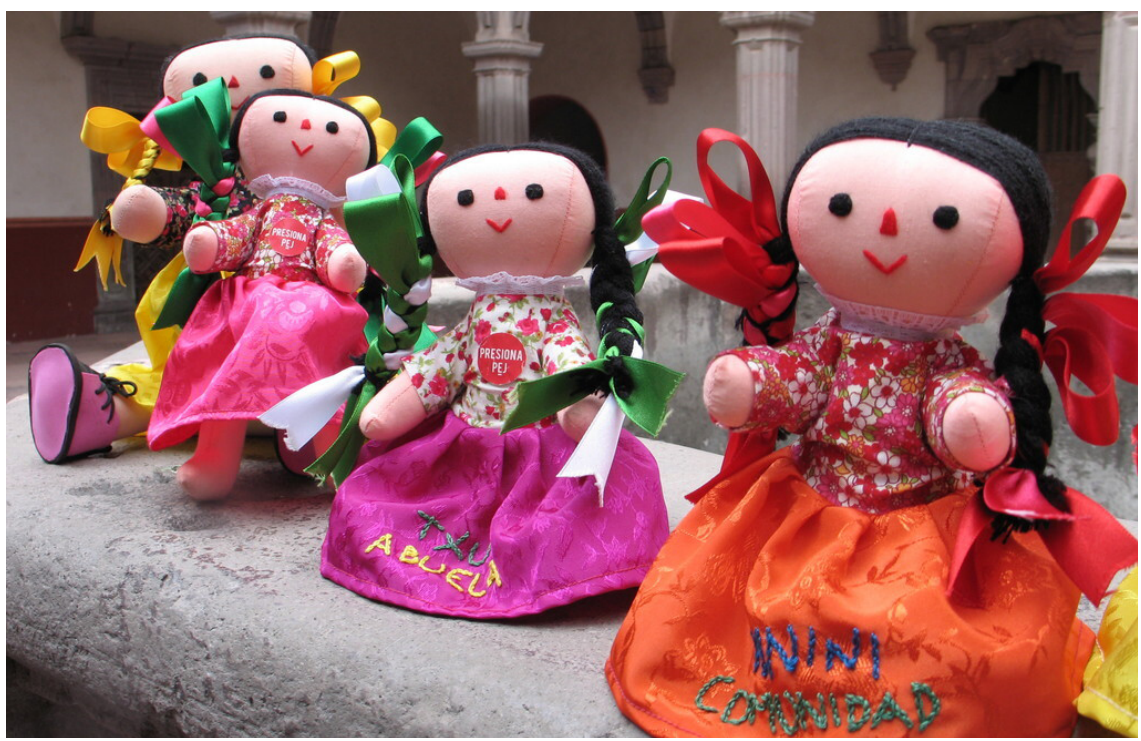

Fuente: (Conacyt prensa, 2016) 
Estos microempresarios han tenido acceso a diversos espacios: centros culturales y educativos les han abierto las puertas, incluso se han presentado en medios de comunicación masiva (como los espacios del gobierno del Estado de Querétaro, que les apoyó con difusión) 3 para dar a conocer "su" producto. Paradójicamente, un gran número de mujeres indígenas siguen vendiendo esta clase de muñecas en las vías públicas de ciudades como Querétaro, en medio de los enfadosos regateos y del acoso de los inspectores municipales.

Desde nuestro punto de vista, los microempresarios de Yosoyoho están lucrando con un objeto que condensa elementos importantes para los otomíes de Amealco, no solo con las muñecas, sino también con el idioma nativo, pues las frases en dicha lengua resultan ser un plus mercadotécnico, banalizando la importancia del reconocimiento de la cultura de los pueblos indígenas y el rescate de sus lenguas.

¿Es posible que las muñecas Xahni, cuyos costos oscilan entre los $\$ 400$ y $\$ 600$ pesos, que se venden por internet y algunas tiendas del centro de la ciudad de Querétaro, puedan coadyuvar a que las y los hablantes del otomí "conserven" su lengua, o que los niños tengan interés por aprender el idioma nativo? ¿Quiénes podrían tener acceso a estas costosas muñecas? Al parecer, no se está buscando que Xahni llegue a un alto número de personas que hablan o entienden otomí, sino a las personas que puedan comprarla. Entonces ¿en dónde está la revitalización, si no es accesible para los grupos que hablan o entienden la lengua?

\section{El Festival Nacional de Muńecas Artesanales}

En el año 2013 se realizó el primer Festival Nacional de la Muñeca Artesanal e Indígena en la cabecera municipal de Amealco, Querétaro, el cual fue impulsado por la Comisión Nacional para el Desarrollo de los Pueblos Indígenas (CDI) — ahora Instituto Nacional de los Pueblos Indígenas (INPI) - Para ese primer evento, no solo fueron convocadas artesanas de la región, sino también de distintos estados de la República, quienes se trasladaron a dicho lugar para exponer sus creaciones artesanales con el fin de venderlas.

El objetivo de este Festival, según lo expresado por la entonces delegada general de la CDI, Nuvia Mayora Delgado, fue "impulsar a las mujeres para generar empleos a través de proyectos productivos” (NTX, 2013). En

\footnotetext{
${ }^{3}$ Ver GobQro, 2016.
} 
esa ocasión la delegada anunció que la CDI, junto con el Fondo Nacional de las Artes (Fonart), buscaría conseguir la patente de "la muñeca artesanal mexicana", refiriéndose a la "muñeca de bola", que, como ya lo mencionamos, se produce en varios estados, principalmente entre poblaciones otomíes y mazahuas.

A partir de 2013 se han realizado en la misma cabecera municipal distintas ediciones del Festival. En todas, se ha invitado a mujeres de otras entidades y, a partir de ediciones recientes, se invitaron a delegaciones de artesanos de otros países. El Festival sigue siendo convocado por el ahora INPI, pero también destacan en su organización y convocatoria el Ayuntamiento Municipal, el Gobierno del Estado, la Secretaría de Turismo y la Secretaría de Desarrollo Sustentable. Las dependencias y agentes convocantes administran los espacios en los cuales los artesanos venden sus productos, organizan eventos y espectáculos, y llevan a cabo un concurso donde los artesanos participantes quedan agrupados en cuatro categorías: mejor muñeca en textil, muñeca en fibras vegetales, muñeca en alfarería y, por último, los nuevos diseños.

En estos festivales el Ayuntamiento les cobra a los artesanos, tanto del municipio como de otras partes del país, el uso del espacio de la plaza principal para la venta de sus creaciones. En cada edición se ha podido apreciar una mayor inversión publicitaria y con ello, más flujo de turistas.

En un primer momento puede parecer que la realización de este evento representa un avance en el reconocimiento de la diversidad cultural, en la valoración de los conocimientos y cosmologías indígenas, reflejadas en sus creaciones artesanales, o la preocupación de las dependencias del Estado por generar espacios de encuentro con los artesanos. No obstante, se observa una estrategia donde se hace uso mediático de lo que se asocia con "el tema indígena”, como la muñeca y las artesanías, para poder lucrar con esto desde una lógica y funcionamiento vertical.

Este tipo de organización tiene varios matices e implicaciones. Sin duda los artesanos salen beneficiados al vender sus creaciones en este espacio; sin embargo, en una sociedad capitalista como la nuestra, las personas que detentan el poder político y económico son las más beneficiadas, ya que acumulan más capital económico a partir del turismo que llega a la zona por el atractivo artesanal. 
Consideramos que estas políticas de desarrollo, que tienen como eje el fomento al turismo, utilizan el tema de la diferencia cultural o "el tema indígena” como estrategia de mercadotecnia. En este contexto, el patrimonio cultural de las sociedades tradicionales tiende a transformarse en producto de consumo (Ariel de Vidas, 2002: 7). Así, en el Festival de la Muñeca Artesanal la lógica que impera es la del mercado, tomando a las creaciones originarias como meros productos atractivos, donde la etiqueta de "indígena" es un plusvalor, pero vaciándolo de contenido.

\section{La muńeca otomí y su incidencia en la declaratoria de Amealco como Pueblo Mágico}

Más arriba se anticipó que en la última década se ha desarrollado un plan que busca consolidar al municipio de Amealco como destino turístico. Para afianzar esta proyección, que responde a los intereses de la clase política y empresarial local, se ha desplegado una importante estrategia publicitaria en torno a la muñeca otomí, presentándola como una suerte de símbolo vinculado con las raíces indígenas del municipio.

Durante la administración municipal 2015-2018, encabezada por Rosendo Aguilar, presidente municipal electo del Partido Acción Nacional (PAN), se elaboró el expediente para solicitar a la Secretaría de Turismo el nombramiento de Amealco como Pueblo Mágico. En una entrevista que sostuvimos con Víctor Eduardo Ruíz, director del Departamento de Turismo, mencionó que en el expediente-solicitud se subrayó la elaboración de las muñecas, explicó que "hay como 150 puntos que tienes que responder o documentar o demostrar

que los tienes. El atractivo simbólico, que es el más central, es precisamente el valor cultural de la muñequita” (Ruíz, 2018).

El 15 de agosto de 2018, en un evento público en la plaza principal de Amealco, el gobernador del estado de Querétaro, Francisco Domínguez Servién, ratificó la declaratoria de la "Muñeca Artesanal de Amealco como Patrimonio Cultural de Querétaro", misma que fue publicada el 18 de abril de 2018 en el Diario Oficial del Estado de Querétaro (La sombra de Arteaga, 2018). Más tarde, el 12 de octubre de 2018, la Secretaría de Turismo le otorgó el nombramiento de Pueblo Mágico a la cabecera municipal de Amealco. 
Ilustración 3. Video mapping sobre la parroquia de Santa María, Amealco.

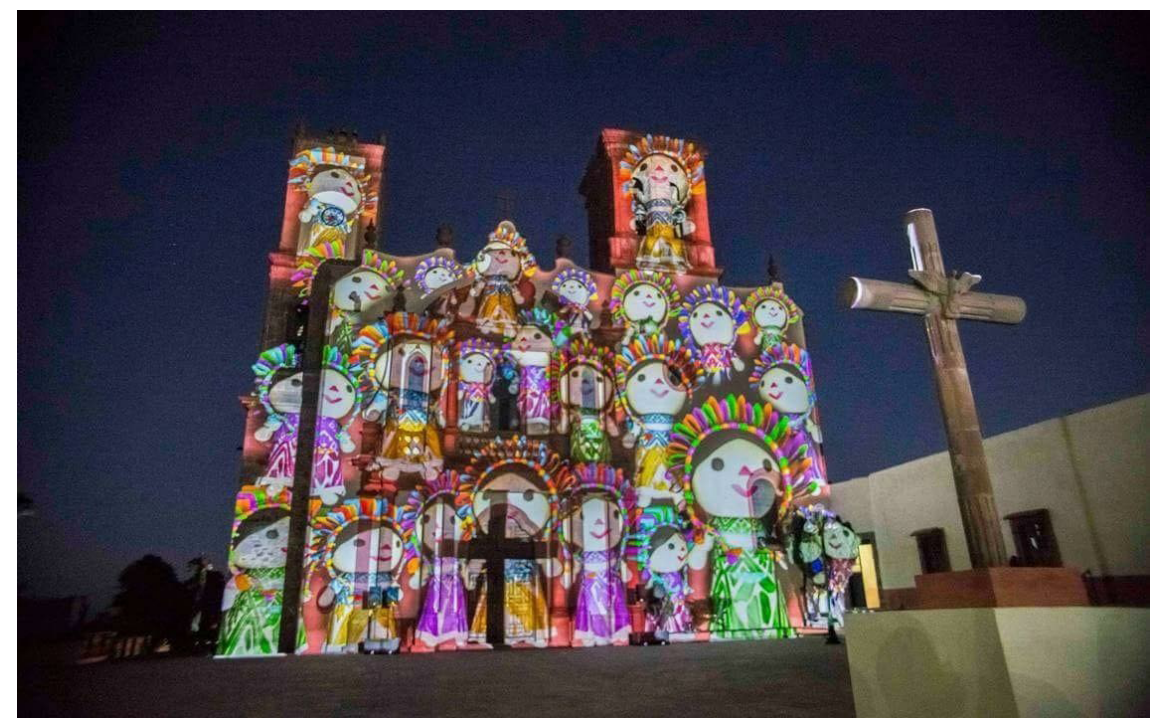

Fuente: 10 cosas que hacer en el Pueblo Mágico de Amealco, Querétaro (Gámez, 2018).

Como ya se mencionó, fue principalmente el uso mediático de la muñeca otomí lo que permitió solicitar el nombramiento de Pueblo Mágico. Durante este proceso la cabecera municipal se transformó de manera significativa. Las calles cercanas a la plaza fueron "rehabilitadas": volvieron subterráneo el cableado, se pintaron las fachadas de casas y negocios en una paleta de colores amarillos, cafés y naranjas; los letreros de negocios se homogenizaron, todos se hicieron de metal, de un mismo tamaño, color y fuente. Se cortaron los árboles para construir una explanada más amplia, se modificaron las jardineras y se colocaron tres esculturas doradas que representan a la muñeca tradicional. En algunos andadores se pusieron adoquines que simulan las figuras de los bordados realizados en las comunidades otomíes. A partir de la declaración de Amealco como Pueblo Mágico, sobre la fachada de la iglesia se proyecta un video mapping a manera de espectáculo nocturno, en el cual se pueden apreciar diversas imágenes de las muñecas y otros elementos asociados con los otomíes, como las danzas, las fiestas, los trajes tradicionales, etc.

Aun con el énfasis de los "elementos indígenas", este nuevo diseño del espacio trajo consigo mayor regulación y control hacia la actividad comercial ambulante de los otomíes. Solo a algunos artesanos se les otorgaron pequeños 
locales movibles (llamados convencionalmente carritos), y a otros (solo a seis familias de todo el municipio) se les prestó un espacio en una casona, que ahora se ha convertido en el mercado de artesanías.

La patrimonialización de la muñeca otomí, aunada a la declaratoria de Amealco como Pueblo Mágico, forma parte de una política multiculturalista que reconoce la diversidad, pero al mismo tiempo traza las formas de interacción con ella. Uno de los objetivos de dicho nombramiento fue delimitar los espacios en donde se encuentran los "legítimos" artesanos, aquellos que tienen el derecho de elaborar y, por ende, comercializar la muñeca. Asimismo, fue una estrategia para reconocer a los otomíes de Querétaro como herederos de esta creación frente a otros pueblos otomíes y mazahuas, como los del Estado de México, que también tienen una larga data creando las muńecas. La declaratoria de patrimonio es un acto que busca consolidar a Amealco como "cuna de la muñeca", para afianzar la conexión entre ésta y el pueblo, y con ello propiciar el arribo turístico.

Ante esto, las inconformidades no se hicieron esperar. Por distintos medios, la comunidad de Santiago Mexquititlán se ha pronunciado como el verdadero origen de la muñeca. Raúl Benito, joven oriundo de ese lugar, lo expone de la siguiente manera:

Mi tía y una amiga comentan que [la muñeca] comenzó a hacerse desde 1972. Ellas, como muchas comunidades indígenas emigraban al Estado de México [...] el Instituto Indigenista dijo en ese momento: "las tenemos en las calles, debemos hace algo para que ya no, como dijeron en Querétaro, ya no afeen la ciudad". Entonces hacen un departamento en donde les enseñan oficios, bordar y eso, y entre ellos la elaboración de un muńequito. $\mathrm{Y}$ ya la gente en algún momento dijo: "ya podemos hacerlo por nuestra cuenta" y así. Una señora relata: "hubo alguien que agarró los moldes, pero no los agarró todos, agarró los moldes, pero a nosotros nos costó vestirla, nos costó peinar", las adecuaron hasta hacer una copia, y ya al hacer la copia le pusieron toques de la comunidad como tal (Santiago Mexquititlán, 24/07/18).

La muñeca es de Santiago, concluyó Raúl en la conversación que sostuvimos. Algunas personas de esa comunidad mencionan que "los de Amealco", es decir, los habitantes de la cabecera municipal quieren robarse el nombramiento de 
"cuna de la muñeca". Varios pobladores cuentan la historia de los talleres en la Ciudad de México, subrayan que las mujeres de la comunidad tomaron el diseño inicial y lo adecuaron.

Es claro que entre los habitantes de Santiago Mexquititlán se conformó una noción de patrimonio a partir las acciones gubernamentales; ellos se reconocen como sujetos con legitimidad para hacer uso de la muñeca, pues es parte de "su patrimonio". En esto también se aprecian ideas sobre la colectividad, los derechos de uso y los deberes que ellos tienen de mantener y transferir esos conocimientos a generaciones futuras. Asimismo, se percibe un reforzamiento de la identidad étnica revelada ante el aprovechamiento que las dependencias gubernamentales y otros actores han hecho de la muñeca.

\section{La muñeca Lele}

La declaratoria de la Muñeca Artesanal de Amealco como Patrimonio Cultural de Querétaro prepararía el terreno para la creación de Lele, apelativo que significa "bebé" en hñönhö, y que el Gobierno del Estado de Querétaro promovió como un genérico para llamar a las muńecas otomíes, pero en particular a una muñeca monumental de aproximadamente seis metros de altura, que durante el año 2019 emprendería una "gira” por Shanghái, Sídney, Madrid, Londres, Montreal y Chicago. En este recorrido, Lele se presentó como "embajadora cultural" de Querétaro ante el mundo. El objetivo era atraer al turismo internacional $-\mathrm{y}$ la posible inversión extranjera- hacia la entidad, aprovechando la figura de la muñeca indígena.

El regreso de Lele al país se celebró el 8 de agosto de 2019 en el marco del $18^{\circ}$ Encuentro de Culturas Populares y Pueblos Indígenas, llevado a cabo en la cabecera municipal de Amealco. Para el mes de diciembre la muñeca monumental hizo presencia en la primera Feria de la Muñeca Otomí de la Ciudad de México. En ese evento se vendían llaveros, tazas y otros suvenires con la imagen de Lele.

Dicha muñeca resultó tan rentable que, para septiembre de 2019, hubo quien intentó registrar la marca Lele y la imagen de la muñeca tradicional ante el IMPI (Instituto Mexicano de la Propiedad Industrial). Ese fue el caso de un empresario de León, Guanajuato. En consecuencia, Marco del Prete Tercero, secretario de desarrollo sustentable, declaró que el nombre de Lele no era del Gobierno de Querétaro sino "de los que habitamos Querétaro", 
por lo que tendría que ser defendido "con toda la fuerza posible". Reconoció que tanto el nombre como la muñeca otomí fueron parte de una campaña de promoción turística y cultural de la entidad en el mundo, hecho que le daba al Gobierno de Querétaro "el derecho del primer uso de la marca” (Velázquez, 2019). Fue así que el Gobierno del Estado emprendió una disputa contra el empresario por ganar los derechos de autoría. A saber, los habitantes de Santiago Mexquititlán no se quedaron con los brazos cruzados y en cuanto se percataron de lo sucedido, también se hicieron presentes ante el IMPI para reclamar su reconocimiento como comunidad creadora de la muñeca otomí.

Ilustración 4. Lele, la muñeca monumental en el atrio de la parroquia de Santa María, Amealco.

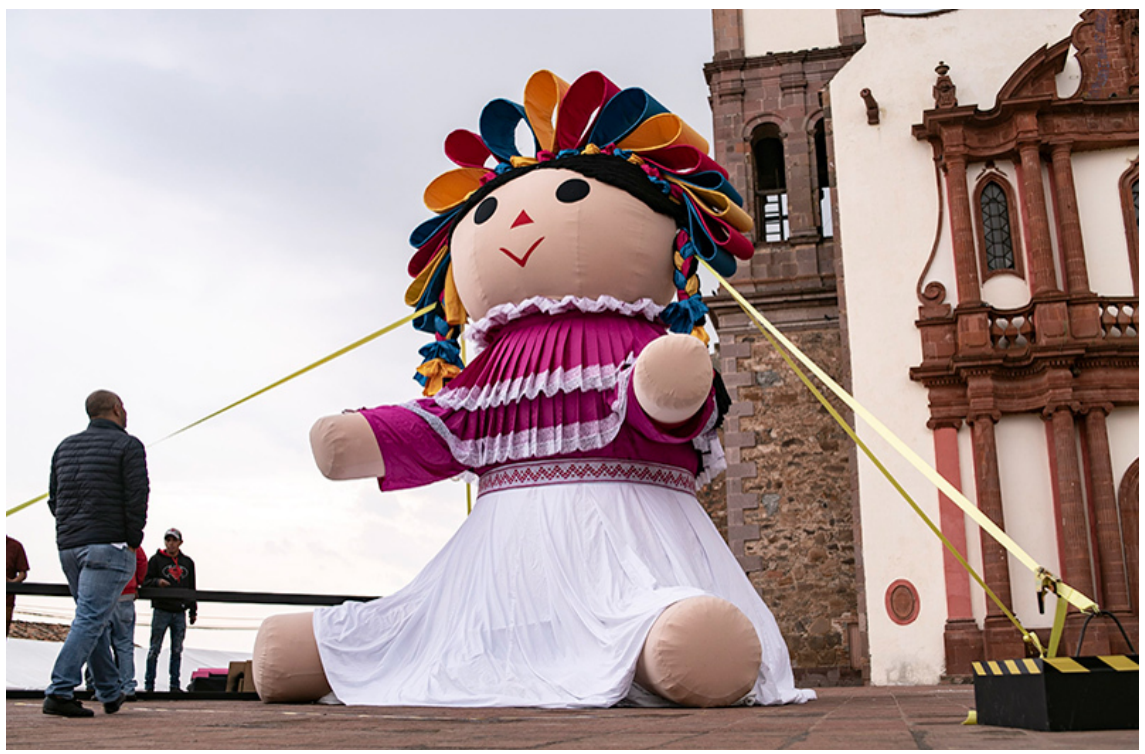

Fuente: (Gobierno de Queretaro, 2019)

Lo suscitado nos lleva a reflexionar sobre la imperante necesidad del reconocimiento de las propiedades intelectuales colectivas, lo que se traduce en el derecho que tienen los pueblos indígenas de administrar y manejar su patrimonio. Para diciembre de 2019, senadores mexicanos propusieron la Ley General de Salvaguardia de los Elementos de la Cultura e Identidad 
de los Pueblos y Comunidades Indígenas, Afromexicanas y Equiparables, entendiendo la salvaguardia como:

el conjunto de medidas de carácter jurídico, técnico, administrativo y financiero para la preservación y enriquecimiento de los elementos de la cultura e identidad de los pueblos y comunidades (...) que incluyen, entre otras acciones, la identificación, documentación, investigación, protección, promoción, valorización, transmisión y revitalización de esos elementos (Galván, 2019).

Dicha Ley tendrá que ser turnada a la Cámara de Diputados para su posterior votación y aprobación. La propuesta permitirá que sean las propias comunidades las que señalen qué elementos se consideran disponibles a terceros y cuáles no. La Ley en cuestión plantea que la reproducción, copia o imitación de los elementos de los pueblos indígenas sin autorización, así como incumplir los términos de la licencia otorgada por las comunidades para el uso, aprovechamiento, comercialización o explotación de elementos, serán sancionados por el Instituto Nacional del Derecho de Autor (Indautor) con hasta diez ańos de prisión (ídem).

Si bien queda mucho por hacer, consideramos que el reconocimiento de propiedades intelectuales colectivas en los aparatos legislativos —más que el decreto de Leyes Generales de Cultura - ampararía a los creadores de cultura más desfavorecidos y contribuiría a la legitimación de sus derechos como autores.

En el discurso de los políticos queretanos se decía que Lele invitaba a exaltar la memoria y la trascendencia de las raíces, y que era "símbolo de lo mexicano". La secretaria de cultura del estado, Paulina Aguado Romero, comentó que "gracias a ese proyecto las artesanas de Amealco lograron incrementar tanto precios como ventas", igualmente dijo que "la gente quiere tenerla dentro de sus objetos de valor", por ello la compraban. Argumentó que "el principal proyecto es dignificar, promover, preservar todo lo que tiene que ver con nuestros pueblos originarios, la promoción de la lengua madre" (López, 2019).

No obstante, Adela Martín, representante de los artesanos de Santiago Mexquititlán, argumentó que el Gobierno del Estado nunca los consultó sobre 
la elaboración de la muñeca, y agregó: "Creo que el gobierno se expropió (sic) de la palabra 'Lele'. Ya nos la robó por ponerle así a la muñeca”. Asimismo, expresó que la invención de Lele perjudicó a los artesanos de las comunidades indígenas más que favorecerlos: "Todos dicen que vayan a visitar el Pueblo Mágico, más se olvidan de las mujeres indígenas y de los pueblos originarios, que es de donde viene la muñeca [...] En Amealco no viven mujeres otomíes, no se fabrican muñecas, se olvidan de Santiago y San Ildefonso" (García, 2019: 8).

El viaje de Lele por varias ciudades del globo, y el subsecuente intento para registrarla como marca, nos muestra que la relación que el Estado establece con lo étnico sigue trazándose en términos utilitarios; la diversidad es vista como un recurso y una mercancía. ¿Qué promueve Lele? A Querétaro como destino de inversión turística. El ímpetu de la reivindicación de la multiculturalidad depende entonces de su rentabilidad, y la folclorización de las expresiones otomíes del sur de Querétaro resulta ser un insumo para promover la inversión del capital.

\section{Consideraciones finales}

En el México posrevolucionario, el reconocimiento y respeto a la diversidad de grupos indígenas era una postura que resultaba contraria a la pretensión de crear un "país moderno" y de llegar al "desarrollo". Actualmente, en el marco de las políticas extractivistas, el reconocimiento de la llamada diversidad cultural ha tomado un rumbo que le es útil al mercado, donde los mayores beneficiados no necesariamente son las personas que asumen una identidad étnica.

En las últimas décadas las políticas del Estado mexicano han estado estrechamente ligadas a proyectos empresariales que han tratado de convertir "el tema indígena" en un campo rentable, susceptible de ser mercantilizado. Estas políticas de "reconocimiento" resultan ser una plataforma discursiva que permite el despliegue de prácticas extractivistas, puesto que a menudo las expresiones culturales con mayor promoción (como las danzas, artesanías, fiestas, etcétera) son tomadas como meros productos comerciales, banalizando y desestimando los significados, los conocimientos y relaciones que se aglutinan alrededor. 
¿Por qué se eligió a la muñeca otomí para construir políticas de patrimonialización y difusión comercial? Consideramos que esto obedece principalmente a dos aspectos estrechamente ligados. El primero se relaciona con "lo rentable" que puede ser un objeto que se exotiza, una "etnomercancía". Desde el discurso oficial se preconizan algunas características de la muñeca, como su carácter "artesanal", se destaca que en ella se condensan "conocimientos ancestrales" e incluso se ha llegado a decir que ha sido el juguete de las niñas otomíes por generaciones. También se menciona que su venta ha sido importante para el sustento de muchas mujeres otomíes durante años, pero regularmente esto se romantiza al hacer énfasis en la perseverancia y tenacidad frente a las condiciones económicas adversas. La muñeca otomí permite poner "el tema indígena" sobre la mesa, acentuando elementos que conllevan una visión esencialista, y con ello, se evita generar una reflexión más profunda sobre las desigualdades.

El segundo aspecto se vincula con su viabilidad comercial. Se trata de un producto consolidado en el mercado y bien apreciado por los consumidores. En estos términos, solo bastaba mayor publicidad sobre "el lugar de origen" y resaltar que estas acciones buscan el "bienestar social" de los grupos indígenas, para lograr la derrama económica esperada.

Como se puede apreciar en este caso, la muñeca como elemento fuertemente arraigado a los otomíes, es resaltado mediáticamente como indígena y, en este contexto, es expoliado para convertirse en un recurso que posibilita el aumento de ingresos generados por el turismo masivo, sin importar las afectaciones sociales, ambientales y económicas para los pobladores de municipio.

Aunque en este texto se ha discutido el extractivismo llevado a cabo por académicos, empresarios y dependencias gubernamentales, no podemos ignorar que dicha práctica también se encuentra presente al interior de las mismas poblaciones otomíes. Es innegable que hay artesanos que también capitalizan creaciones y conocimientos de su cultura. A pesar de ello, aún se advierte una desventaja entre el beneficio que estos saberes le dejan a los grandes capitales -y sus estrategias de marketing-, frente al beneficio que obtienen microempresarios indígenas. Así pues, resultaría problemático equiparar el extractivismo exógeno con el incipiente extractivismo practicado entre los propios artesanos otomíes, aun con todas las diferencias que hay 
entre los que se encuentran más respaldados por las instituciones y los menos favorecidos.

En las prácticas extractivistas del ámbito cultural se observa una tendencia a la destrucción de saberes, conocimientos y formas de pensar/sentir el mundo, en la medida que la producción y/o distribución de estas creaciones están bajo la traza de las lógicas de rentabilidad capitalista, donde la derrama económica beneficia principalmente a los grupos de la clase política y empresarial, y al mismo tiempo, sostiene un esquema social inequitativo y desigual.

\section{Bibliografía}

Acosta, Alberto (2016) "Aporte al debate: El extractivismo como categoría de saqueo y devastación”, Fiar. Vol. 9, pp. 25-33.

Acosta, Alberto (2012) "Extractivismo y neoextractivismo: dos caras de la misma maldición”, Ecoportal, 25 de julio de 2012. Disponible en:https:// www.ecoportal.net/temas-especiales/mineria/extractivismo_y_ neoextractivismo_dos_caras_de_la_misma_maldicion/?cn-reloaded $=1$ (consultado el 04 de abril de 2020).

Alerta Qro (2019) "Este fin se realiza el Festival Nacional de Muñecas Artesanales en Amealco", Alerta Qro. Disponible en: https://www. alertaqronoticias.com/2019/11/15/este-fin-se-realiza-el-festivalnacional-de-munecas-artesanales-en-amealco/ (consultado el 31 de marzo de 2020).

Ariel de Vidas, Anath (2002) Memoria textil e industria del recuerdo en los Andes: Identidades a prueba del turismo en Perú, Bolivia y Ecuador. Quito: Ediciones Abya-Yala.

Arizpe, Lourdes (1979) Indígenas en la Ciudad de México: el caso de las "Marías".

México: Secretaría de Educación Pública. 
Borja Cruz, Julio César (2017) Entre flores y listones. Un estudio antropológico de la Danza de Mujeres en San Ildefonso Tultepec, Amealco. Tesis para obtener el grado de Licenciatura en Antropología, Universidad Autónoma de Querétaro.

Castillo, María del Carmen (2017) "La blusa de Tlahuitoltepec Xaam nïxuy es identidad” en Galicia, Érica (ed.) Acervo mexicano, legado de culturas. Sevilla: Universidad Pablo de Olavide, Benemérita Universidad Autónoma de Puebla. pp. 170-191.

Comaroff, John y Comaroff, Jean (2011) Etnicidad S.A. Madrid: Katz, Conocimiento.

Conacyt Prensa (2016) "Xahni: la muñeca que habla español y otomí”, Lado $B$. Disponible en: https://ladobe.com.mx/2016/05/xahni-la-munecaque-habla-espanol-y-otomi/ (consultado el 15 de abril de 2020).

Galván, Melissa (2019) "El Senado aprueba la ley que protege los diseños indígenas", Expansión Política. Disponible en: https://politica. expansion.mx/congreso/2019/12/03/el-senado-aprueba-ley-queprotege-los-disenos-indigenas (consultado el 04 de enero de 20).

Gámez, Claudia (2018) "10 cosas que hacer en el Pueblo Mágico de Amealco, Querétaro", Espiritu Aventurero. Disponible en: https:// revistaaventurero.com.mx/conoce-mexico/10-cosas-que-hacer-en-elpueblo-magico-de-amealco-queretaro/ (consultado el 04 de abril de 2020).

García, Alan (2019) "Lelé perjudicó a Santiago Mexquititlán, cuna de la muñeca otomí: representante de artesanos", Tribuna de Querétaro. No. 932.

García Canclini, Néstor (1981) Las culturas populares en el capitalismo. La Habana: Casa de las Américas.

Gobierno del Estado de Querétaro (2016) Muñeca Xahni [video] Disponible en: https://www.youtube.com/watch?v=PLc5M--G_hM (consultado el 01 de abril de 2017). 
Gómez Martínez, Arturo (2012) “El águila bicéfala y la configuración mitológica de San Pablito", Estudios de Cultura Otopame, Núm. 8, pp. 107-125.

Grosfoguel, Ramón (2016) 'Del 'extractivismo económico' al 'extractivismo epistémico' y al 'extractivismo ontológico': una forma destructiva de conocer, ser y estar en el mundo", Tabula Rasa, Núm. 24, pp.123-143. Gudynas, Eduardo (2015) Extractivismo. Ecología, economía y politica de un modo de entender el desarrollo y la Naturaleza. Bolivia: Centro Latino Americano de Ecología Social.

La sombra de Arteaga (2018) "Sumario", en La sombra de Arteaga, Periódico oficial del Gobierno del Estado de Querétaro. No. 31, p.11702, fecha de publicación: 18 de abril de 2018.

López, Zulema (2019) "Muñeca Lele maravilla al mundo e impacta en redes", El Universal. Disponible en: https://www.eluniversalqueretaro. $\mathrm{mx} /$ sociedad/muneca-lele-maravilla-al-mundo-e-impacta-en-redes (consultado el 02 de abril de 2020).

México Desconocido (2019) "La gigante Lele estará en la primera Feria de la Muñeca Otomí en la CDMX”, México Desconocido. Disponible en: https://www.mexicodesconocido.com.mx/primera-feria-de-lamuneca-otomi-en-la-cdmx.html (consultado el 05 de abril de 2020).

Novelo, Victoria (1976) Artesanias y capitalismo en México. México: Secretaría de Educación Pública, Instituto Nacional de Antropología e Historia.

NTX (2013) "Organizan primer festival nacional de muñecas artesanales e indígenas", Informador.mx. Disponible en: https://www.informador. $\mathrm{mx} /$ Cultura/Organizan-primer-Festival-Nacional-de-MunecasArtesanales-e-Indigenas-20131116-0022.html (consultado el 24 de diciembre de 2017).

Oehmichen Bazán, Cristina (2015) Identidad, género y relaciones interétnicas. Mazahuas en la Ciudad de México. México: Universidad Nacional Autónoma de México. 
Pérez Díaz, Fidel (2015) "El caso del plagio de la blusa xaam nïxuy de Santa María Tlahuitoltepec", Ojarasca, Suplemento del diario la Jornada. Disponible en: http://www.jornada.unam.mx/2015/12/12/oja-santa. html, (consultado el 06 de enero de 2020).

Romer, Marta (2013) "Las migrantes otomíes en la ciudad de México: el trabajo en la calle como una vía de inserción urbana”, Boletín Oficial del Instituto Nacional de Antropología e Historia. México: INAH, núm. 96, pp. 58-68.

Ruíz, Víctor Eduardo (2018) Comunicación personal. 10de agosto de 2018. Tomás, Antonia (2014) Comunicación personal. 15de agosto de 2014.

TvUAQ (2016) "Muñecas otomíes Yosoyoho, con Román Souza y Alfredo Reyes", Presencia Universitaria, Universidad Autónoma de Querétaro [video]. Disponible en: https://www.youtube.com/ watch?v=qSMgDRQw6FM (consultado el 01 de abril de 2017).

Velázquez Ramírez, Francisco (2019) "Defenderán nombre de Lele ante intento de empresario para registrarlo", Código Qro. Disponible en: http://codigoqro.com.mx/2019/09/04/defenderan-nombre-de-leleante-intento-de-empresario-para-registrarlo-2/ (consultado el 02 de abril de 2020). 